RIEGO, Cristián "La expansión de las facultades de las víctima en la Reforma Procesal Penal y con posterioridad a ella".

Polít. crim. Vol. 9, No 18 (Diciembre 2014), Art. 11, pp. 668-690.

[http://www.politicacriminal.cl/Vol_09/n_18/Vol9N18A11.pdf]

\title{
La expansión de las facultades de la víctima en la Reforma Procesal Penal y con posterioridad a ella
}

\author{
Cristián Riego \\ Profesor Universidad Diego Portales \\ cristian.riego@udp.cl
}

\section{Resumen}

El artículo contrasta el proceso de reconocimiento de los derechos de la víctima que tuvo lugar durante la reforma que introdujo el sistema acusatorio en el año 2000, con el que ha venido ocurriendo con posterioridad a ese proceso y que se ha traducido en una serie de propuestas de reforma legal, en una reforma constitucional y en litigación frente al Tribunal Constitucional. Se plantea que no existe continuidad entre ambos fenómenos, sino que se trata dos orientaciones muy distintas, basadas en ideas contrastantes e incluso hasta cierto punto contradictorias, detallándose además cómo, de prosperar algunas o todas las líneas de reforma posteriores al año 2000, el sistema procesal penal chileno se encontraría en una situación bastante única y en ningún caso prevista por los promotores de las reformas originales.

Palabras clave: Proceso penal, víctimas, persecución penal.

\begin{abstract}
This paper contrasts the process of recognition of the victim's rights in the Chilean criminal procedure reform, which was introduced alongside the new accusatorial system in the year 2000 , with the one that has occurred after that, which has consisted in several proposals for legal reforms, in a constitutional reform and in litigation before the Constitutional Court. The paper discusses the hypothesis that there is no continuity among the two phenomena, which are based in opposing understandings of the issues at hand. Finally, there is a description of how, if some or all of the new reform proposals that affect the victim's rights are implemented, the Chilean criminal procedure will face a unique situation, and one that was in no way foreseen by promoters of the original reforms.
\end{abstract}

Key words: Criminal procedure, victim's rights, prosecution.

\section{Introducción}

El Nuevo Código Procesal Penal estableció el año 2000 una regulación de los derechos de la víctima y, en especial, de sus facultades de participación en el proceso, más generosa que la que había existido tradicionalmente en Chile, dando cuenta de una tendencia doctrinaria que en ese momento era muy influyente. No obstante, esa regulación no ha tendido a 
RIEGO, Cristián "La expansión de las facultades de las víctima en la Reforma Procesal Penal y con posterioridad a ella".

consolidarse. Por el contrario, la tendencia persistente ha sido hacia un cuestionamiento del rol definido para la víctima en el nuevo sistema procesal penal y a la ampliación de sus facultades por la vía de modificaciones legales y constitucionales, por la de la litigación ante el tribunal constitucional y por la del establecimiento de provisión gratuita de servicios legales a las víctimas.

El objetivo del trabajo es el de validar la hipótesis de que no existe continuidad entre los procesos de desarrollo de los derechos de la víctimas que tuvieron lugar al momento de establecerse el nuevo sistema penal acusatorio y el que se ha desarrollado con posterioridad. Tanto el sentido como los fundamentos de ambos procesos son diferentes e incluso, en alguna medida, contradictorios. Sostendremos que, de prosperar algunas o todas las orientaciones del segundo de los procesos descritos, el sistema procesal penal chileno pasaría a quedar configurado de un modo bastante único a nivel comparado y, en cualquier caso, muy lejano a las previsiones de quienes promovieron los derechos de las víctimas en el periodo de la reforma original.

El trabajo se divide en tres secciones. En la primera se describe en qué consistió el proceso de reconocimiento de derechos de la víctima en el nuevo Código Procesal Penal, que entró a regir en el año 2000, y explica las ideas y los argumentos que le dieron sustento.

En la segunda se pretende mostrar cuáles han sido los desarrollos legales, constitucionales y jurisprudenciales posteriores al año 2000, de los derechos de la víctima. Este capítulo no pretende discutir dogmáticamente cada uno de estos desarrollos, que por lo demás no se han concretado sino parcialmente en el sistema legal chileno, sino solo mostrar el vigor que ha tenido la tendencia en pro de mayores facultades de participación de las víctimas y cuáles han sido sus contenidos. En la tercera sección, de conclusiones, el trabajo pretende perfilar el nuevo escenario que se generaría a partir de un avance sustantivo de las nuevas ideas de expansión de derechos de la víctima que se han planteado con posterioridad la reforma del año 2000.

\section{La reforma y la participación de la víctima.}

\subsection{Los derechos consagrados en el Código Procesal Penal. ${ }^{1}$}

El Nuevo Código Procesal Penal, aprobado en el año 2000 por medio de la ley 19.696, introdujo un importante conjunto de normas destinadas a hacerse cargo de las necesidades de las víctimas en el proceso penal. De hecho, el reconocimiento de los derechos de la víctima y la promoción de sus intereses concretos constituyó uno de los principales objetivos del proceso de reforma. ${ }^{2}$

\footnotetext{
${ }^{1}$ Una exposición detallada de los derechos de la víctima en el nuevo proceso penal en: CASTRO, Javier, "La Víctima y el Querellante en la Reforma Procesal Penal", Revista de Derecho de la Pontificia Universidad Católica de Valparaíso, XXV (2004), pp. 127-141.

${ }^{2}$ HORVITZ LENNON, María Inés; LOPEZ MASLE, Julián, Derecho Procesal Penal Chileno Tomo I, Santiago: Editorial Jurídica de Chile, 2002, p. 281.
} 


\section{Polít. crim. Vol. 9, № 18 (Diciembre 2014), Art. 11, pp. 668-690. \\ [http://www.politicacriminal.cl/Vol_09/n_18/Vol9N18A11.pdf]}

Este componente del proceso de reforma estuvo vinculado a un movimiento que en esa misma época estaba teniendo lugar en diversas partes del mundo y que estaba orientado a reconocer a la víctima como un sujeto importante en el sistema penal, después de mucho tiempo en que su presencia se había encontrado disminuida como producto de la definición de la persecución penal como una actividad puramente estatal. ${ }^{3}{ }^{4}{ }^{4}{ }^{5}$ Este movimiento no tenía el sentido de incentivar el rol de la víctima como promotora de la punición sino más bien las de promover las posibilidades del remplazo de la pena por la reparación y la de otorgar a las víctimas derechos colaterales a la persecución como el de buen trato o protección y simbólicos como el reconocimiento de su protagonismo en el conflicto.

En el período de discusión del proceso de reforma, las principales cuestiones que se debatían en relación con la víctima estaban vinculadas a su participación como acusador adhesivo y al reconocimiento de la reparación como una forma apropiada de resolución de algunos conflictos penales, además de algunos otros derechos de menor significación en cuanto a los objetivos del proceso penal, como son el acceso de la víctima a la información del proceso y el derecho del ofendido a ser protegido durante el proceso. ${ }^{6}{ }^{7}$

Durante el periodo de discusión de las reformas al proceso penal que tuvieron lugar en diversos países de América Latina al mismo tiempo que en Chile, Maier se manifestaba partidario de reconocer un rol importante a las víctimas en los nuevos sistemas procesales, debido, en primer lugar, a la necesidad de reconocerla como una protagonista del conflicto que se pretende resolver por medio del proceso y, además, como una manera de evitar el riesgo de burocratización de los ministerios públicos en el cumplimiento de su nuevo rol de persecución. ${ }^{8}{ }^{9}$

El tema de la reparación recibió mucha atención y que fue objeto de importantes debates. Roxín, por ejemplo, sostenía que el reconocimiento de la reparación en reemplazo total o

\footnotetext{
${ }^{3}$ Una expresión paradigmática de este movimiento es la Declaración de las Naciones Unidas de 1985, "Sobre los Principios Básicos de Justicia Para las Víctimas del Crimen y de Abuso de poder".

${ }^{4}$ Una descripción general en LARRAURI, Elena, "Victimología", en: VV. AA., De los Delitos y de las Víctimas, Buenos Aires: Ad-Hoc, 1992, pp. 281-316.

${ }^{5}$ Sobre este movimiento en los EE.UU.: DIRK DUBER, Markus "La víctima en el derecho penal estadounidense", en: REYNA ALFARO, Luis Miguel (Dir.), Derecho, Proceso penal y Victimología, Mendoza: Ediciones Jurídicas Cuyo, 2003, pp. 23-58.

${ }^{6}$ Entre los antecedentes de esta tendencia en Chile: DUCE, Mauricio; RIEGO Cristián, "El Proceso Penal y los Derechos Humanos: las Víctimas de los Delitos en el Proceso Penal Chileno", en: DUCE/RIEGO, El proceso penal y los derechos humanos, Santiago: Universidad Diego Portales, 1994, pp. 123-166.

${ }^{7}$ Una descripción mas general de la discusión en: ESSER, Albin, "Acerca del Renacimiento de la víctima en el procedimiento penal, tendencias nacionales e Internacionales", en: VV. AA., De los delitos y de las Víctimas, Buenos Aires: Ad-Hoc, 1992, pp. 14-52.

${ }^{8}$ MAIER, Julio, “La víctima y el sistema penal”, en: VV. AA., De los delitos y de las Víctimas, Buenos Aires: Ad-Hoc, 1992, pp. 221.

${ }^{9}$ Es necesario tener presente que, a diferencia de lo que ocurrió en Chile, en la mayoría de los demás países de América Latina la función de perseguir los delitos fue asumida por Ministerios Públicos preexistentes y cuya práctica anterior estaba limitada al cumplimiento de funciones dictaminadoras. Ver, por ejemplo, DUCE, Mauricio, "El Ministerio Publico en la Reforma procesal penal en América Latina: visión general acerca del estado de los cambios", Sistemas Judiciales No 8 (2005), Buenos Aires: Centro de Estudios de Justicia de las Américas, 2005, p. 67.
} 
RIEGO, Cristián "La expansión de las facultades de las víctima en la Reforma Procesal Penal y con posterioridad a ella".

parcial de la pena podía satisfacer de manera apropiada los fines de la misma en algunos casos. ${ }^{10}$ Las ideas en pro de la aceptación de la reparación fueron acogidas, con expectativas más altas, incluso por autores de orientación abolicionista, quienes abrigaban la esperanza de que, al recuperar la víctima el protagonismo en cuanto a la decisión de su conflicto y poder aceptar una variedad de respuestas, incluyendo las de carácter reparatorio, ello pudiese, junto con otros cambios sustantivos, conducir a una reducción de los sistemas penales $^{11} \mathrm{o}$ de los castigos en su forma tradicional. ${ }^{12}$

Siguiendo los planteamientos de la doctrina de la época, el artículo 6 del Nuevo Código enunció una regla general referida a la víctima, estableciendo un deber de protección por parte del Ministerio Público, un deber general de protección de sus derechos por parte de los jueces y un deber de trato por la policía y demás organismos auxiliares. ${ }^{13}$ Por su parte, el párrafo 6 del libro primero del Código reguló con detalle los derechos de participación de la víctima, la que accede a ellos sin ningún requerimiento formal y que se expanden significativamente en el caso de que esta decida constituirse en querellante, lo que está regulado en el párrafo 7 .

Siguiendo la línea del antiguo Código de Procedimiento Penal, se reconoció a la víctima, en los delitos de acción pública, la posibilidad de constituirse en acusador particular en adhesión o ampliación de la acusación del fiscal. Pero el nuevo Código fue más lejos, puesto que reconoció la facultad del querellante para acusar aún en contra de la posición del fiscal, previa autorización del juez, ${ }^{14}$ mediante el llamado forzamiento de la acusación. A pesar de que no lo dice expresamente, la lógica del procedimiento parece indicar claramente que esta posibilidad está condicionada a que el Ministerio Público hubiese previamente presentado cargos frente al juez mediante la llamada formalización de la investigación.

Además, se estableció un importante reconocimiento e incentivo a la reparación de la víctima por medio de los llamados acuerdos reparatorios, ${ }^{15}{ }^{16}$ los cuales dan lugar al sobreseimiento definitivo de la causa en un grupo de delitos, además de mantenerse, aunque en una versión restringida, la posibilidad de la demanda civil en el proceso penal ${ }^{17}$.

\footnotetext{
${ }^{10}$ ROXIN, Claus, "La reparación en el sistema de los fines de la pena", en: VV.AA., De los Delitos y de las Víctimas, Buenos Aires: Ad-Hoc, 1992, p. 155.

${ }^{11}$ BOVINO, Alberto, "La víctima como preocupación del abolicionismo penal", en: VV.AA., De los Delitos y de las Víctimas, Buenos Aires: Ad-Hoc, 1992, p. 279.

${ }^{12}$ CRISTIE, Nils, "Los conflictos como pertenencia", en: VV.AA., De los Delitos y de las Víctimas, Buenos Aires: Ad-Hoc, 1992, p. 174.

${ }^{13}$ Esta norma se amplió por la ley 19789 del año 2002, que estableció además un deber para el fiscal de promover la reparación de la víctima.

${ }^{14}$ Artículo 258 del Código Procesal Penal.

15 Artículo 241 y siguientes del Código Procesal Penal.

16 Sobre los acuerdos reparatorios y sus fundamentos: VIDELA BUSTILLOS, Lino, "Los acuerdos reparatorios a la luz del concepto de reparación”, Revista de Estudios de la Justicia, año 13 (2000), pp. 293321.

${ }^{17}$ Artículos 59 y siguientes del Código Procesal Penal.
} 
En general, la línea seguida por el Código Procesal Penal, en el sentido de establecer la posibilidad de que la víctima intervenga en el proceso como querellante y acusador particular, estuvo especialmente influida por las opiniones de Maier, principal promotor de las reformas en diversos países de América Latina y autor principal del Código Procesal Penal Modelo. ${ }^{18}$ En ese modelo se plantea la figura del querellante adhesivo en el articulo 78 y la posibilidad de la demanda civil reparatoria en el artículo 87. Parece claro que, además de la opiniones académicas tenidas en cuenta durante la discusión del Nuevo Código, fue también importante la consideración de que desde muy antiguo, y como producto de la influencia española ${ }^{19}$ nuestra legislación establecía la figura del querellante, que permitía a las víctimas de los delitos constituirse en actores procesales importantes e incluso en acusadores con cargos diferentes o por encima de los de la acusación principal, siempre dependiendo del ejercicio de la acción pública por parte del Juez de instrucción. Por otra parte, esta figura de la querella privada en delitos de acción pública cobró una enorme relevancia durante la dictadura militar y en los años posteriores, debido a la experiencia ocurrida en los casos de crímenes vinculados a las violaciones a los derechos humanos, donde las autoridades judiciales en general no realizaron las investigaciones respectivas. ${ }^{20}$ En estos casos, fueron las querellas presentadas y sostenidas por los familiares de las víctimas y las organizaciones de derechos humanos las que permitieron que los delitos fueran a lo menos documentados formalmente ante el sistema judicial y con posterioridad pudiesen ser perseguidos por los jueces cuando las circunstancias políticas e institucionales fueron favorables.

Estas dos influencias, por una parte una tendencia doctrinaria a favor del reconocimiento de Derechos de la víctima, y por otra parte, circunstancias locales vinculadas a la tradición de la querella ${ }^{21}$ y su práctica, determinan que desde un inicio el proceso de reforma asuma como uno de sus contenidos centrales el de los derechos de la víctima y, más específicamente, la ampliación de las posibilidades de participación de la víctima en el proceso penal.

Vale la pena resaltar que el proceso penal chileno ha ido en esto más lejos que los países con las tradiciones jurídicas más importantes. Si bien es cierto que en muchos países ha existido un fuerte impulso hacia el reconocimiento de diversos derechos a favor de las víctimas, ese desarrollo no se ha traducido, como entre nosotros, en facultades de participación en el ejercicio de la acción penal pública, la que se ha mantenido reservada a agentes estatales con exclusividad, o a lo menos reservando el protagonismo a los órganos

\footnotetext{
${ }^{18}$ Sin duda el más influyente fue el Código Procesal Penal Modelo para Iberoamérica elaborado por el Instituto Iberoamericano de Derecho Procesal en 1989.

${ }^{19}$ Sobre la querella y la acción popular en España: PÉREZ GIL, Julio, La Acusación popular. Tesis doctoral Universidad de Valladolid, Valladolid, 1997, 758 páginas.

${ }^{20}$ Informe de la Comisión de Verdad y Reconciliación, Tomo I, Santiago: 1991, pp. 91-93.

${ }^{21}$ En el Código procesal penal se hizo un cambio en cuanto a la titularidad de la querella que no afecta directamente a la víctima. Mientras en el antiguo Código de Procedimiento Penal se consagraba en el Artículo 10 la acción popular de manera general, en el nuevo Código la querella se reservó de manera general solo a la víctima en el artículo, manteniéndose la acción popular solo para los delitos terroristas y algunos cometidos por funcionarios públicos.
} 
RIEGO, Cristián "La expansión de las facultades de las víctima en la Reforma Procesal Penal y con posterioridad a ella".

de persecución penal pública, como ocurre, por ejemplo, en los de tradición anglosajona. ${ }^{22}$ Así, por ejemplo, en el sistema de los EE. UU. no existe la posibilidad de que la víctima participe de ningún modo en la persecución: esa es una función reservada de modo exclusivo a los fiscales. ${ }^{23}$ En el caso de Alemania, la víctima tiene la posibilidad de participar en el juicio, pero siempre subordinada a la acusación del fiscal y no se le reconoce la facultad de presentar una acusación propia. ${ }^{24}$

\section{La expansión de la participación de la víctima con posterioridad a la reforma.}

Durante los años de vigencia del nuevo sistema procesal penal se ha producido una situación paradojal. Por una parte, el nuevo Código incorporó un conjunto bastante sustantivo de derechos para la víctima, y, por la otra, se ha producido un efecto de insatisfacción respecto del reconocimiento de la víctima en el sistema. ${ }^{25}$

Desde los primeros momentos de vigencia del nuevo sistema y en especial a partir del desarrollo del nuevo proceso por medio de las audiencias públicas, se generó la idea de que la víctima se encontraba en una posición disminuida. ${ }^{26}$ Desde el punto de vista de una percepción externa, en las audiencias de las diversas etapas del proceso tiene lugar una discusión entre el fiscal y el imputado quedando la víctima en una posición relativamente marginal. Por otra parte, el imputado, quien desde la perspectiva de la percepción pública aparece como el sujeto que genera menos simpatías, es aquel al que la ley entrega mayores posibilidades de participación, entre las que destaca la provisión de un abogado defensor financiado por el estado, lo que no ocurre respecto de la víctima.

Esta percepción se ha expresado de varias maneras. La organización de Víctimas de la Delincuencia, liderada por Gonzalo Fuenzalida. ${ }^{27}$ Entre las ideas de esta ONG, que ha promovido diversas manifestaciones públicas a favor de las víctimas, ha estado

\footnotetext{
${ }^{22}$ Existen algunas excepciones a esta tendencia, pero bastante marginales. Por ejemplo: en Inglaterra y en Canadá, a pesar de que ambos países cuentan con órganos de persecución penal pública, teóricamente la víctima podría iniciar una persecución privada si es que estos órganos no han actuado y si es que la ley no reserva la persecución a algún órgano público. En la práctica, esta facultad se ejerce muy excepcionalmente. BURNS, Peter, "Private Prosecutions in Canada: The Law and a Proposal for Change", McGill Law Journal, vol. 21, n 2 (1975), pp. 269-297. Existen otros ejemplos, más bien vinculados a la posibilidad de la víctima de participar en ciertos debates específicos, por ejemplo, en 2001 en Irlanda se autorizo la participación de la víctima, representada por un abogado, en los procesos por delitos de violación, pero solo para la discusión acerca de la introducción al juicio de prueba sobre su historia sexual. DOAK, Jonathan, "Victims rights in criminal trials: prospects for participation", Journal of Law and Society, vol. 32, n 2 (June 2005), p. 296.

${ }^{23}$ Una explicación del estatus de la víctima en el proceso penal en los EE.UU. en: LAMBORN, LeRoy L., "Victim Participation in the Criminal Justice Process: The proposals for a Constitutional Amendment", Wayne Law Review, vol. 34 (1987-1988), p. 136.

${ }_{24}^{24}$ Artículos 395 y ss. del Código Procesal Penal Alemán.

${ }^{25}$ Pareciera ser que esto es una tendencia común a otros países, por ejemplo: KELLY, Deborah P., "Delivering Legal Services to Victims: an evaluation and prescription", Justice System Journal Vol. 9 (1984), pp. 62-86.

${ }_{26}^{26}$ PIEDRABUENA RICHARD, Guillermo, "Cómo Proteger Mejor los Intereses de las Víctimas y de esta manera contribuir a la Disminución de la Delincuencia", Rev. chil. derecho, vol. 36, n 3 (2009), pp. 671-677.

${ }^{27}$ Elegido Diputado el año 2014 por el distrito 54 de la región de los Ríos.
} 
precisamente la de la disparidad entre víctima e imputado por la falta de representación legal de esta última. ${ }^{28}$

Otra de las circunstancias que favoreció esta crítica fue la postura adoptada por el Ministerio Público al respecto. El primer fiscal nacional, Guillermo Piedrabuena, no adoptó una doctrina institucional de cercanía con los intereses de las víctimas, sino que se preocupó más bien de delimitar su responsabilidad, con el objetivo de buscar argumentos legales para sostener que los físcales no eran de ningún modo los abogados de las víctimas. ${ }^{29} \mathrm{Si}$ bien es cierto que en un análisis estrictamente jurídico el punto de vista del fiscal puede tener argumentos en su favor, desde el punto de vista comunicacional contribuyó a generar la percepción de que la víctima se encontraba en una situación vulnerable.

Este escenario ha favorecido la generación de diversas iniciativas destinadas a fortalecer la posición de la víctima en el proceso penal. Este conjunto de iniciativas o propuestas son bastante heterogéneas y operan a diversos niveles: algunas veces responden a problemas concretos de personas específicas, otras a iniciativas legislativas de tipo general. No obstante sus diferencias, pensamos que es posible hablar de un desarrollo que presenta algunos elementos comunes que son importantes de identificar para precisar el efecto que pueden producir sobre el conjunto del sistema de justicia penal.

\subsection{El tribunal constitucional y los derechos de las víctimas.}

Un escenario importante donde se ha expresado la insatisfacción con la extensión de los derechos de participación de las víctimas en el proceso penal ha sido el Tribunal Constitucional.

Desde un primer momento, el tribunal ha mostrado apertura a un reconocimiento de facultades importantes para las víctimas de los delitos. Cuando le correspondió la etapa de control preventivo de la reforma al Código Orgánico de Tribunales, que formó parte del conjunto de leyes que constituyeron la reforma al proceso penal, ${ }^{30}$ un grupo de tres ministros hizo una prevención para que fuera considerada por los legisladores al momento de dictar el Código Procesal Penal que aun no había sido aprobado. ${ }^{31}$ En su voto los ministros formulan un planteamiento que expresa algunas ideas que están presentes en

\footnotetext{
${ }^{28}$ Esta organización convocó el año 2007 a una campaña de recolección de firmas para lograr que el estado provea de defensores a las víctimas. Ver en: http://manuelgross.bligoo.com/content/view/81919/Víctimas-dela-delincuencia-Campana-de-firmas.html

${ }^{29}$ El ex fiscal Piedrabuena ha continuado abogando por esta tesis aún después de su salida del Ministerio Público, llamando la atención sobre la carencia de un abogado financiado con fondos públicos que facilite su participación en el proceso. Por ejemplo: "El derecho constitucional de las víctimas", El Mercurio, 14 de octubre de 2012, p. A2 y "Quién defiende a las víctimas"; El Mercurio, 11 de noviembre de 2012, p. A2. También en una carta titulada "Derechos de las Víctimas", publicada en El Mercurio el 28 de diciembre de 2013.

${ }^{30}$ Ley 19.665 del año 2000.

${ }^{31}$ Prevención de los ministros Jordán, Colombo y Verdugo en la sentencia rol 304-03 del 3 de febrero del año 2000.
} 
RIEGO, Cristián "La expansión de las facultades de las víctima en la Reforma Procesal Penal y con posterioridad a ella".

varios de los desarrollos que estamos tratando de describir. Señalan, así, que la nueva ley presenta aspectos problemáticos, puesto que al definir las funciones del Juez de Garantía, se otorga a la protección de los derechos del imputado una posición central en tanto que a los derechos la víctima se los agrupa junto a los de los demás intervinientes. En opinión de los ministros, la víctima debiera encontrarse en una posición de igualdad respecto del imputado. Al mismo tiempo afirma que la víctima tiene derecho a que el delito se investigue y a que se condene a los culpables.

Con posterioridad, el Tribunal Constitucional se ha referido en diversas ocasiones a las facultades de intervención de las víctimas en el proceso penal. La mayoría de los casos resueltos por el Tribunal en esta materia se han referido al cuestionamiento de la regulación legal que condiciona la posibilidad de forzar la acusación por parte del querellante a que el fiscal haya formalizado la investigación. ${ }^{32}-{ }^{33}$ El Código Procesal Penal, en el artículo 258, permite que el querellante, que por regla general es la víctima, pueda acusar en aquellos casos en que el fiscal decide no hacerlo y plantea el sobreseimiento de la causa o toma la decisión de no perseverar. No obstante, para que esa situación se produzca es necesario que previamente se haya formalizado la investigación en los términos del artículo 229. El problema para el querellante ocurre en los casos en que el fiscal no formaliza, es decir cuando la investigación se mantiene abierta pero sin que el fiscal tome una decisión acerca de si llevar adelante o no la persecución contra una persona determinada.

El cuestionamiento de constitucionalidad ha recaído sobre el artículo 230 del Código Procesal Penal que indica: "El fiscal podrá formalizar la investigación cuando considerare oportuno formalizar el procedimiento por medio de la intervención judicial” es decir, pareciera claro que la formalización es una decisión discrecional del fiscal.

Esta regulación limitativa de la posibilidad de que la víctima ejerza la acción penal sería contraria a la disposición del artículo 83 inciso segundo de la Constitución Política del Estado que reconoce, después de regular el ejercicio de la acción penal por el Ministerio Público, que: "El ofendido por el delito y las demás personas que determine la ley podrán ejercer igualmente la acción penal".

Las soluciones concretas que el tribunal ha dado a los casos en que se ha planteado este conflicto han variado en el tiempo. En una de sus resoluciones el tribunal declaró la inconstitucionalidad del artículo 230 del Código Procesal Penal, en cuanto se aplique como una facultad discrecional para el Ministerio Público que le permite a este no formalizar pero

\footnotetext{
${ }^{32}$ Una exposición de la evolución de los criterios del Tribunal Constitucional en este tema en: BORDALI SALAMANCA, Andrés, "La acción penal y la víctima en el Derecho chileno", Revista de Derecho de la Pontificia Universidad Católica de Valparaíso, n ${ }^{\circ} 37$ (2011), pp. 513-545. También: AGUILERA BERTUCCI, Daniela, "La Participación de la Víctima en la Persecución Penal Oficial: Análisis a Partir de la Jurisprudencia del Tribunal Constitucional”, Revista Derecho Universidad Católica del Norte, vol. $18, \mathrm{n}^{\circ} 2$ (2011), pp. 51-72.

${ }^{33}$ Se han planteado también otros debates sobre la extensión de derechos de las víctimas, aunque no con tanto impacto sobre su intervención en la persecución penal. Por ejemplo, sobre el derecho de la víctima a apelar sobre la resolución de excusión de prueba: Fallos 1535 de 2010, 1502 de 2010 y 2330 de 2013.
} 
tampoco tomar las otras decisiones que la ley prevé para poner término a la causa, ${ }^{34}$ es decir el tribunal considera inconstitucional que se aplique el artículo 230 como una facultad que le permita al fiscal no resolver la causa y dejar así a la víctima en la imposibilidad de ejercer sus facultades. Esa comprensión vulneraría los derechos que la constitución reconoce a la víctima para ejercer la acción penal, los que derivan del inciso segundo del artículo 83, de la noción de tutela jurisdiccional efectiva, de la garantía de justo y racional procedimiento y de una investigación racional y justa consagrados en el artículo $19 \mathrm{~N} 3$ de la Constitución Política del Estado.

La sentencia en cuestión recae sobre un caso de delitos económicos entre personas privadas, en el que existe una clara disparidad de criterios entre el fiscal y el querellante en cuanto al mérito del caso. En ese contexto, la pretensión del querellante de llevar adelante la persecución privada de un caso que considera suficientemente respaldado probatoriamente, aparece bloqueada por la negativa del fiscal a formalizar, el que incluso pidió al juez un sobreseimiento que fue rechazado por razones formales sin que el fiscal tomara otras determinaciones sobre el caso.

No sería riguroso afirmar que al declarar inconstitucional una cierta aplicación del artículo 230, en cuanto permitiría un ejercicio discrecional de la facultad de formalizar, la sentencia abre una puerta a la posibilidad de un ejercicio autónomo de la acción penal por parte de la víctima. Si bien el contenido de la decisión es limitado en ese sentido por la precisión con que el tribunal establece que solo declara inconstitucional una interpretación muy precisa del artículo 230, abre la posibilidad de una compresión del fallo a favor de la autonomía del querellante en el ejercicio de la acción penal, idea que aparece fortalecida por algunos argumentos contenidos en la sentencia, en especial el reconocimiento del derecho a la tutela judicial efectiva para la víctima. ${ }^{35}{ }^{36}$ En ese mismo sentido el tribunal es muy enfático al establecer, en el considerando cuarto del fallo, que:

“...cabe concluir que cualquier razonamiento que conduzca a privar a la víctima de su derecho a ejercer la acción penal, dando así eficacia a su decisión de contar con un proceso jurisdiccional donde se le haga justicia, por causa de decisiones del ministerio público, ha de ser descartado, pues subordina el derecho de acceder a los tribunales a las decisiones del persecutor estatal, con lo cual se la priva, de esa forma, del derecho a la acción que le confiere el numeral 3 del artículo 19 de la Carta Fundamental, en concordancia con el artículo 83 de la misma"

No obstante, en resoluciones posteriores la posición del Tribunal ha sido menos enfática, reconociendo el derecho de la víctima al ejercicio de la acción pero reconociendo también

\footnotetext{
${ }^{34}$ Sentencia Rol 815-08 del año 2008.

${ }^{35}$ Considerandos decimo primero y duodécimo segundo, sentencia Rol 850-2008.

${ }^{36}$ A favor de esta noción: MATURANA MIQUEL, Cristián; MONTERO LOPEZ, Raúl, Derecho Procesal Penal Tomo I, Santiago: Abeledo Perrot Legal Publishing, 2010, p. 296. En contra: BORDALI SALAMANCA, Andrés, "No hay ejercicio del Derecho Fundamental de acción en el Proceso Penal: Sentencia del tribunal Constitucional que declaró inaplicable el Artículo 230 del Código Procesal Penal", Rev. derecho (Valdivia) [online], vol. 21, $\mathrm{n}^{\circ} 2$ (2008), pp. 205-250 [visitado el 05.09.2014]. Disponible en: http://dx.doi.org/10.4067/S07-0950200800200009
} 
RIEGO, Cristián "La expansión de las facultades de las víctima en la Reforma Procesal Penal y con posterioridad a ella".

la validez de la limitación constituida por el requerimiento de la previa formalización y el reconocimiento de que esta es una facultad del fiscal de acuerdo al artículo $230 .{ }^{37} \mathrm{El}$ tribunal ha interpretado que la ley otorga al querellante otras posibilidades de ejercer su derecho, por ejemplo por medio de lo dispuesto en el artículo 186 del Código Procesal Penal, el cual podría ser usado por el querellante para presionar al fiscal para que formalice y le permita así acusar. Esta norma se ha interpretado tradicionalmente como una facultad que permite a quien sospecha o conoce estar imputado en un proceso pedir al juez que le ponga un plazo para formalizar con miras a evitar la prolongación ilimitada de una investigación desformalizada en su contra. ${ }^{38}$

El efecto que estos fallos han tenido sobre el sistema procesal penal es limitado. La decisión más fuerte que declaró la inconstitucionalidad del artículo 230 estuvo limitada a un caso específico, y el cambio en la composición del tribunal y en sus mayorías ha hecho que el contenido de las decisiones haya ido variando hacia posiciones que no cuestionan el control del Ministerio Público sobre el ejercicio de la acción penal por medio de su facultad de formalizar.

Sin embargo, existe la posibilidad de que la mayoría en el tribunal constitucional pueda variar, y que se vuelva a imponer el criterio de estimar que el artículo 230 es inconstitucional en algún sentido, derivándose de allí la posibilidad de un ejercicio autónomo de la acción penal por parte de la víctima.

No pretendemos en esta sección discutir sustantivamente el mérito de los criterios desarrollados por el tribunal constitucional, sino solamente mostrar cómo, por la vía de sus fallos y sobre todo de algunos argumentos que utiliza, se puede proyectar con alguna plausibilidad un escenario en que se cuestione el control estatal de la acción penal pública y, de ese modo, se vayan generando espacios para un ejercicio crecientemente autónomo de la acción penal por parte de las víctimas.

\subsection{La reforma constitucional y la Defensoría de las Víctimas.}

La noción de la falta de protagonismo de la víctima y su debilidad en el nuevo proceso penal derivó pronto en la idea de que dicha carencia estaba vinculada al hecho de que las facultades procesales que se le reconocen en el Código Procesal Penal, no podían ser ejercidas en la práctica debido a la muy limitada oferta de de abogados que presenten querellas de modo gratuito en nombre de las víctimas. ${ }^{39}$ Efectivamente, las víctimas ejercen

\footnotetext{
${ }^{37}$ Sentencia Rol 1542-09 del año 2010. También en contra de la inconstitucionalidad del artículo 230, las sentencias 1244 del 2008, 1337 del 2009, 1341 del 2009, 1380 del 2009, 1445 del 2009, 1467 del 2009 y 2510 del año 2014.

${ }^{38}$ Existe a lo menos un fallo en que los tribunales penales han rechazado explícitamente la posibilidad de aplicar el artículo 186 a favor de la Víctima: Corte de Apelaciones de La Serena, Rol 243-2014

${ }^{39}$ Ver por ejemplo las opiniones del Senador Alberto Espina en el reportaje: "Espina: Víctimas de delitos están abandonadas como perros callejeros", La Tercera, 25 de noviembre de 2008 http://www.latercera.com/contenido/654_78050_9.shtml
} 
sus facultades procesales en muy pocos casos, en general solo en delitos graves ${ }^{40}$ cuando cuentan con los recursos para pagar un abogado o cuando alguna agencia estatal ${ }^{41} \mathrm{u}$ organización privada $^{42}$ les provee con ese servicio por alguna razón específica.

A partir de esa constatación y de la noción de la que imputado y víctima deben recibir un trato igualitario en el proceso penal ${ }^{43}$ se desarrolló la idea de igualar la posición de la víctima a la del imputado en términos de acceso a servicios de representación legal. Después de varios años de discusión, la ley 20516 del año 2011 estableció una nueva disposición constitucional en el artículo 19 N 3 que indica:

"La ley señalará los casos y establecerá la forma en que las personas naturales víctimas de delitos dispondrán de asesoría y defensa jurídica gratuitas, a efecto de ejercer la acción penal reconocida por esta Constitución y las leyes."

La nueva norma constitucional establece solo un principio general cuya aplicación está condicionada a la ley y hasta ahora su implementación no parece haber sido una prioridad importante. No obstante, resulta claro que a partir de una disposición constitucional como esta resultara fácil impulsar a favor de una política que masifique la prestación de servicios de asistencia legal a las víctimas, que derive a su vez en la presencia masiva de abogados querellantes financiados por el estado a lo menos en algún grupo importante de procesos.

\subsection{Proyectos de ley destinados a fortalecer las facultades de las víctimas.}

En los primeros años de vigencia del nuevo sistema procesal penal, el tema de las facultades de la víctima no fue objeto de proyectos de reforma importantes. No obstante, a partir de la vigencia del nuevo sistema, en la ciudad de Santiago se han venido planteando sucesivas iniciativas legislativas destinadas a fortalecer su participación en el proceso penal. Muchas de estas iniciativas se refieren a temas muy específicos y no han tenido demasiado apoyo en el proceso legislativo; no obstante, nos parece necesario revisarlas brevemente para poner en evidencia una serie de ideas que tienden a repetirse y que se van consolidando en proyectos más significativos que pueden llegar a concretarse.

\footnotetext{
${ }^{40}$ Ver: BAEZ, Danilo, "La eficacia del querellante en el juicio oral: estudio empírico en el quinquenio de entrada en vigencia de la reforma procesal penal en la región metropolitana", en: FUENTES, Claudio (Coord.), Diez Años de la Reforma Procesal Penal en Chile, Santiago: Ediciones Universidad Diego Portales, 2011, pp. 191-241. Además, los antecedentes empíricos dan cuenta de que en la experiencia concreta del sistema de justicia penal, la presencia de querellantes no supone un aporte demasiado relevante para la eficacia de la persecución.

${ }^{41}$ Existen algunas agencias estatales que prestan este servicio en ciertos casos, por ejemplo, la Corporación de Asistencia Judicial de la Región Metropolitana provee de abogados que representan a las víctimas en el algunos casos de violencia intrafamiliar o de violaciones a los derechos humanos. Ver https://www.chileatiende.cl/servicios/ver/AK008?\&offset=. También el SERNAM, en casos de agresión sexual contra la mujer, ver: http://portal.sernam.cl/?m=programa\&i=65.

${ }^{42}$ Por ejemplo La Fundación Amparo y Justicia brinda representación legal gratuita, además de otros servicios a los niños o niñas víctimas de delitos sexuales. http://www.amparoyjusticia.cl/

${ }^{43}$ Ver considerandos 6, 7, 8 y 9 de la moción de los Senadores Andrés Allamand Zavala, Alberto Espina Otero, José García Ruminot, Baldo Prokurica Prokurica y don Sergio Romero Pizarro de fecha 16 de octubre, 2007.
} 
RIEGO, Cristián "La expansión de las facultades de las víctima en la Reforma Procesal Penal y con posterioridad a ella".

El año 2007 fueron dos los proyectos referidos a las facultades de las víctimas. En uno de ellos se propuso otorgar facultades a la víctima para intervenir como querellante en el procedimiento simplificado, concediéndole además facultades de intervención en la etapa de determinación de la pena; ${ }^{44}$ en el segundo, se propuso ampliar las facultades de los jueces para proteger a las víctimas en el desarrollo del proceso, estableciéndolo como un deber ${ }^{45}$ y no sólo como una facultad.

El año 2008 se planteó un proyecto estableciendo que la víctima debía ser oída por el juez al momento de la discusión de las medidas cautelares. ${ }^{46}$

El año 2009 se presentaron dos proyectos ${ }^{47}$, ambos proponiendo ampliar al querellante y a otros intervinientes la facultad de apelar la exclusión probatoria del auto de apertura del juicio oral.

El año 2012 se presentó un proyecto ${ }^{48}$ destinado a obligar al fiscal a pronunciarse en diez días acerca de las solicitudes de diligencias planteadas por el querellante y otorgando a este la posibilidad de reclamar ante el Juez de Garantía ante la negativa a llevar a cabo las diligencias solicitadas.

El año 2012, a partir de un caso de mucha notoriedad, el Presidente de la República convocó a una comisión de expertos para modificar el sistema procesal penal con el fin de hacerlo más eficaz en el propósito de reprimir la criminalidad. A principios del año 2013 la voluntad presidencial se tradujo en un proyecto de ley que abordó diversos temas, entre los que se encuentra el fortalecimiento de la posición de la víctima. Entre las propuestas del proyecto destaca la de imponer una obligación para el fiscal de fundamentar su decisión de archivo provisional en aquellos casos en los que se haya identificado un imputado, debiendo, además, cumplirse el requisito de haber realizado previamente diligencias de investigación. También se propone que la víctima y el querellante puedan reclamar ante las autoridades del ministerio público la negativa del fiscal a formalizar. Otra propuesta consiste en que la víctima pueda oponerse a la suspensión condicional del procedimiento cuando exista un interés público prevalente. Finalmente, se propone que el fiscal debe fundar su decisión de no perseverar. ${ }^{49}$

El proyecto descrito ha sido el que de manera más comprehensiva ha abordado la ampliación de facultades de las víctimas y, además, el que ha contado con mayor apoyo para su avance en el proceso legislativo. Es probable que el cambio de gobierno del año 2014 dificulte su avance, dado que el tema no parece estar entre las prioridades de las nuevas autoridades; sin embargo, algunas de las ideas principales del proyecto (y otras

\footnotetext{
${ }^{44}$ Boletín 4798-07 de 4 de enero de 2007.

${ }^{45}$ Boletín 5126-07 de 13 de junio de 2007.

${ }^{46}$ Boletín 6556-07 de 11 de diciembre de 2008.

${ }^{47}$ Boletines 6345-07 de 8 de enero de 2009 y 6507-7 de 12 de mayo de 2009.

${ }^{48}$ Boletín 8505-07 de 13 de agosto de 2012.

${ }^{49}$ Una completa explicación de la gestación y el contenido de este proyecto en: DUCE, Mauricio, "La 'reforma de la reforma procesal penal': análisis de la gestación y contenidos de un proyecto de ley", en: VV.AA., Anuario de Derecho Público, Santiago: Universidad Diego Portales, 2013, pp. 110-144.
} 
semejantes) han sido objeto de nuevas iniciativas legislativas, lo que da cuenta de su vigencia.

El mismo año 2013 se presentó un proyecto destinado a permitir la apelación por parte de la víctima de las decisiones del juez de garantía que no dan lugar a sus reclamaciones en contra de decisiones como el archivo provisional o la facultad de no investigar. ${ }^{50} \mathrm{El}$ año 2014 se presentó un proyecto que plantea que el acuerdo de la víctima sea un requisito de la suspensión condicional del procedimiento ${ }^{51}$ y otro que propone hacer apelable la resolución del juez de garantía que niega lugar al forzamiento de la acusación en caso de existir discrepancia entre el querellante y el fiscal. ${ }^{52}$ También se presentó un proyecto destinado a exigir la notificación a la víctima del cierre de la investigación, otorgándole un plazo para la presentación de la querella. ${ }^{53}$ Finalmente, se han presentado dos proyectos con el propósito de otorgar mayores niveles de protección a las víctimas que comparecen a los juicios orales: uno bastante general, ${ }^{54} \mathrm{y}$ el otro, más específico, en el que se plantean diversos mecanismos como la declaración por video conferencia o incluso que los jueces puedan recibir su declaración fuera de la sala del tribunal. ${ }^{55}$

A pesar de que estas iniciativas no han prosperado hasta ahora, creemos que el conjunto de los proyectos da cuenta de una fuerte presión política orientada a fortalecer el rol de la víctima en el proceso penal en dos sentidos específicos: por una parte, operando como un mecanismo de control de las decisiones del fiscal orientadas en cualquier sentido que sea distinto de la persecución; y, por otra, favoreciendo su intervención como acusador subsidiario para aquellos casos en que el fiscal decida no perseguir.

\subsection{La influencia del derecho internacional en la expansión de las facultades de las víctimas.}

El sistema interamericano de derechos humanos ha enfatizado la importancia de las víctimas $^{56}$ y ha establecido que, respecto de algunos delitos que constituyen violaciones graves de los derechos humanos más importantes, como la vida y la integridad personal, el estado tiene una obligación para con la víctima en términos de investigación, procesamiento y sanción. ${ }^{57}$ En sus decisiones los órganos del sistema interamericano han cuestionado, por ejemplo, las leyes de amnistía que impedían la sanción de graves crímenes contra los ciudadanos de diversos países ${ }^{58} \mathrm{y}$, en general, la posibilidad de la impunidad

\footnotetext{
${ }^{50}$ Boletín 8887-07 de 10 de abril de 2013.

${ }^{51}$ Otro proyecto con una orientación semejante: Cámara de Diputados Boletín 9309-07 del 15 de abril de 2014.

${ }^{52}$ Boletín 9341-07 de 13 de mayo de 2014.

${ }^{53}$ Boletín 9416-07 de 27 de junio de 2014.

${ }^{54}$ Boletín 9427-07. De 27 de junio de 2014.

${ }^{55}$ Boletín 9396-07 de 12 de junio de 3014.

${ }^{56}$ GALDAMES ZELADA, Liliana, "Protección de la víctima, cuatro criterios de la Corte Interamericana de Derechos Humanos: interpretación evolutiva, ampliación del concepto de víctima, daño al proyecto de vida y reparaciones", Rev. chil. derecho, vol. 34, n³ (2007), pp. 439-455.

${ }^{57}$ Ver MEDINA, Cecilia, La Convención Americana: Teoría y Jurisprudencia, Santiago: Edición del Centro de Derechos Humanos de la Facultad de Derecho de la Universidad de Chile, 2005, pp. 99 y 188.

58 GONZALEZ, Felipe, Sistema Interamericano de Derechos Humanos. Transformaciones y desafíos, Valencia: Tirant lo Blanch, 2013, p. 268.
} 
frente a las violaciones más graves de derechos humanos. Estos reconocimientos no implican, en principio, nada respecto de la existencia o no de una participación de la víctima en el ejercicio de la acción penal. Parece lógico deducir que, mientras los deberes de investigación, procesamiento y sanción se cumplan para los delitos que el derecho internacional ha definido, está entregado a la ley nacional determinar si la víctima puede o no participar en el proceso penal respectivo y cuáles serían sus facultades. Sin embargo, el problema es más complejo porque, en la medida en que el derecho de la víctima a la investigación, procesamiento y sanción es reconocido, esta podrá naturalmente reclamar frente al incumplimiento y, en consecuencia, podrá impugnar las decisiones que impliquen de cualquier modo evitar la persecución. Esta reclamación la podrá hacer frente a los órganos internacionales de derechos humanos, pero también debiera poder hacerla ante los tribunales nacionales de acuerdo con la regla del artículo 25 de la Convención Americana de Derechos Humanos, la cual obliga a los estados a permitir a las personas hacer valer sus derechos frente a los tribunales nacionales. Por esta vía podría fundamentarse, entonces, el argumento de que los sistemas legales nacionales deben permitir de algún modo que las víctimas exijan la persecución penal de los delitos que constituyen graves violaciones de los derechos humanos, frente a las autoridades judiciales.

En consecuencia, resulta claro que desde el derecho internacional de los derechos humanos se plantea una exigencia de reconocimiento a la víctima que tiene efectos en el derecho interno. No obstante, no creemos que esta exigencia tenga un efecto directo sobre la estructura del proceso penal, a lo menos en el caso chileno, en cuanto, en primer lugar, se refiere solo a un conjunto de delitos muy graves que en nuestro país han ocurrido solo en circunstancias históricas muy específicas, y, en segundo lugar, no define exigencias específicas sobre el modo en que la víctima puede invocar este derecho, por lo que, en principio, las oportunidades que ofrece para ello el Código Procesal Penal debieran resultar suficientes.

No obstante, hay quienes han criticado los desarrollos recientes de los derechos de las víctimas en la jurisprudencia de la Corte Interamericana de derechos humanos y su influencia sobre algunos tribunales locales. En particular, la crítica plantea que las exigencias de persecución establecidas por los órganos internacionales promoverían una exacerbación de la punitividad y una deslegitimación de diversos valores del sistema de justicia penal que pasarían a constituirse en obstáculos de ese objetivo..$^{59}{ }_{-}^{60}{ }^{61}$

\footnotetext{
59 PASTOR, Daniel, “¿Procesos penales solo para conocer la verdad? La experiencia argentina”, en: PASTOR, Daniel (Dir.), Neopunitivismo y Neoinquisición, Buenos Aires: Ad-Hoc, 2008, pp. 367-428.

${ }^{60}$ GUZMAN, Nicolás, "EL neopunitivismo en la jurisprudencia de la Corte Suprema de la Nación y de la Corte Interamericana de Derechos Humanos: Un pronóstico incierto para el ne bis in idem y la cosa juzgada", en: PASTOR, Daniel (Dir.), Neopunitivismo y Neoinquisición, Buenos Aires: Ad-Hoc, 2008, pp. $203-253$. También PASTOR, Daniel, "La deriva neopunitivista de organismos y activistas como causa del desprestigio actual de los derechos humanos", Jura Gentium Rivista di filosofía del diritto internazionale e della politica globale, 2006, en: http://www.juragentium.org/topics/latina/es/pastor.htm [visitado el 24.09.2014].

${ }^{61}$ SILVA SANCHEZ, Jesús-María, "Una crítica a las doctrinas penales de la lucha contra la impunidad y del derecho de la víctima al castigo del autor”, Revista de Estudios de la Justicia, no 11 (2009), p. 55.
} 


\section{Polít. crim. Vol. 9, № 18 (Diciembre 2014), Art. 11, pp. 668-690. \\ [http://www.politicacriminal.cl/Vol_09/n_18/Vol9N18A11.pdf]}

Maier plantea que, en casos muy graves de violaciones extendidas y sistemáticas de derechos humanos básicos como la vida y la integridad física, cometidos por funcionarios estatales, se puede justificar el reconocimiento de un principio en favor de la punición que tenga prioridad por sobre medidas limitativas de la persecución como las "autoamnistías". Critica, sin embargo, la extensión de esa lógica a otras situaciones que no reúnen esas características. $^{62}$

Si seguimos la lógica de la distinción planteada por Maier, podemos entender que, en buena medida, las críticas a la noción del derecho de la víctima a la persecución y sanción están condicionadas por la excesiva extensión de esa idea más allá de las circunstancias extremas que pudieron haberla justificado. En el caso de la Corte Interamericana de Derechos Humanos, el problema descrito se planteó en el contexto del caso Bulacio. Se trata de una sentencia en la que se condenó a Argentina a continuar con la persecución y sancionar a los responsables de un delito cometido en circunstancias relativamente comunes y en el que, luego de un proceso dilatado e ineficaz, se terminó aplicando la prescripción. ${ }^{63}$

En la sentencia se establece que los familiares de la víctima deberán tener acceso y posibilidad de actuación en todas las etapas de las investigaciones de acuerdo con la legislación nacional. ${ }^{64}$ Además, a propósito de la eventual prescripción del caso, la Corte hace una consideración general respecto de la obligación de sancionar:

"este Tribunal ha señalado que son inadmisibles las disposiciones de prescripción o cualquier obstáculo de derecho interno mediante el cual se pretenda impedir la investigación y sanción de los responsables de las violaciones de derechos humanos. La Corte considera que las obligaciones generales consagradas en los artículos 1.1 y 2 de la Convención Americana requieren de los Estados Partes la pronta adopción de providencias de toda índole para que nadie sea sustraído del derecho a la protección judicial, consagrada en el artículo 25 de la Convención Americana". ${ }^{5}$

En este caso, ya no hablamos de aquellas situaciones más graves ${ }^{66}$ de violaciones de los derechos humanos, vinculadas con crímenes contra la humanidad o con violaciones sistemáticas, en las que podría justificarse una exigencia absoluta de persecución y sanción.

\footnotetext{
${ }^{62}$ MAIER, Julio, Segunda jornada de Derecho Penal, Rancagua: octubre de 2012, segunda ponencia, p. 27.

${ }^{63}$ El caso dice relación con la muerte de un adolescente detenido por la policía a propósito de un evento musical. El joven resulta muerto como producto de golpes que habría recibido en el cuartel policial y las investigaciones que se llevan a cabo resultan infructuosas, produciéndose al final una declaración judicial de prescripción del delito. Corte Interamericana de Derechos Humanos, Caso Bulacio Vs. Argentina, Sentencia de 18 de septiembre de 2003.

${ }^{64}$ Corte Interamericana de Derechos Humanos, Caso Bulacio Vs. Argentina, Sentencia de 18 de septiembre de 2003. Considerando 4 de la parte resolutiva.

${ }^{65}$ Corte Interamericana de Derechos Humanos, Caso Bulacio Vs. Argentina, Sentencia de 18 de septiembre de 2003. Considerando 106.

${ }^{66}$ Llama la atención que en este caso la Corte abandona la expresión "grave" cuando se refiere a las violaciones de derechos humanos que el estado está obligado a sancionar. PARENTI, Pablo, "La Inaplicabilidad de normas de prescripción en la jurisprudencia de la Corte Interamericana de Derechos Humanos", en: VV.AA., Sistema interamericano de protección de los derechos humanos y derecho penal internacional, Montevideo: Konrad Adenauer Stiffung, 2010, p. 217.
} 
RIEGO, Cristián "La expansión de las facultades de las víctima en la Reforma Procesal Penal y con posterioridad a ella".

La resolución de la Corte podría interpretarse en el sentido de una ampliación excesiva del reconocimiento del derecho de la víctima a la sanción, que traería como consecuencia una expansión de esa noción a un grupo bastante amplio de delitos. Sin embargo, la Corte no ha continuado en la línea planteada por el caso Bulacio y en lo sucesivo sus exigencias de persecución y sanción han estado referidas siempre a los casos más graves. ${ }^{67}$

Pensamos que la idea de un derecho de la víctima a la persecución y la sanción no es problemática desde el punto de vista del de justicia penal local, mientras se mantenga referida a las violaciones más graves de los derechos humanos. En el caso de crímenes atroces cometidos desde el poder, parece lógico e inevitable el cuestionamiento de los obstáculos a la persecución que pueden provenir desde el mismo estado involucrado en las violaciones. En ese sentido, no creemos que el desarrollo de los derechos de la víctima producido en el derecho internacional tenga un impacto directo en funcionamiento ordinario del sistema penal local $\mathrm{y}$, en consecuencia, no creemos que, a lo menos en el contexto de la discusión chilena, forme parte de lo que hemos identificado como una nueva tendencia a favor de los derechos de la víctima que puede provocar un cambio sustantivo en nuestro sistema de justicia penal en el tiempo próximo.

No obstante, no cabe descartar que los desarrollos expuestos del derecho internacional puedan tener alguna influencia menos directa o en plazos más largos sobre nuestro sistema de justicia penal. Al establecerse un derecho de la víctima a la investigación, procesamiento y sanción, aunque sea para casos muy excepcionales, se genera un argumento que podría utilizarse para justificar fortalecer las facultades de la víctima en pro de la persecución en situaciones de menor gravedad.

\subsection{Las posiciones doctrinarias sobre la expansión de los derechos de las víctimas posteriores a las reformas procesales penales.}

Tanto las grandes reformas a la justicia penal como el posterior debate acerca de los derechos de las víctimas son fenómenos comunes a la mayor parte de los países latinoamericanos. En algunos de ellos se ha generado un desarrollo doctrinario acerca de esta cuestión. Para efectos de validar la hipótesis que venimos explorando, en el sentido de que no hay continuidad, sino contradicción entre los dos fenómenos, resulta interesante revisar los puntos de vista de dos autores que tiene en común haber sido promotores de las reformas originales en sus respectivos países, pero que tienen visiones divergentes acerca de los desarrollos posteriores.

El profesor Julio Maier, quien ha sido una figura muy influyente en el proceso de reforma tanto en Argentina como en el resto del continente, fue un firme partidario de otorgar mayor protagonismo a la víctima. ${ }^{68}$ Con posterioridad ha variado su postura, ${ }^{69}$

\footnotetext{
${ }^{67}$ PARENTI, “La Inaplicabilidad de normas", cit. nota n 66, p. 220.

${ }^{68}$ MAIER, "La víctima y el sistema penal”, cit. nota ${ }^{\circ} 8$, p. 221.

${ }^{69}$ La postura de Maier ha sido expuesta en distintas presentaciones realizadas en diversos seminarios, pero no se ha traducido en un artículo o libro formal hasta el momento. Registros de esas presentaciones son, por ejemplo: MAIER, Segunda jornada de Derecho Penal, cit. nota n 62, pp. 23-33. Y, MAIER, Julio, "Una
} 
transformándose en un crítico de los derroteros seguidos por el proceso de reconocimiento de derechos de la víctima en los años recientes.

Maier critica fuertemente el cambio que se habría producido entre el planeamiento original sostenido por él, en que la participación de la víctima en la persecución era concebida como accesoria y vinculada a la posibilidad de soluciones no punitivas, y una nueva tendencia que califica de "neopunitivista", en la que la víctima adquiere autonomía y se convierte en un agente que suple al estado en la búsqueda del castigo. ${ }^{70}$

Maier identifica este nuevo desarrollo del protagonismo de la víctima con una serie de consecuencias negativas, entre las que resalta un cuestionamiento de los derechos del imputado, los que entran en contradicción con los que tendría la víctima, ${ }^{71}$ y una absolutización de la pena como respuesta ${ }^{72}$ frente a diversos conflictos sociales. ${ }^{73}$

Por su parte, el profesor Sampedro-Arrubla, quien fue uno de los principales promotores de la reforma a la justicia penal en Colombia, continúa planteando la necesidad de fortalecer la posición de la víctima en el ejercicio de la acción penal. ${ }^{74}$ De hecho, plantea la necesidad de una reconstrucción del sistema de justicia penal a partir del protagonismo de las víctimas. A diferencia de Maier, el planteamiento de Sampedro-Arrubla critica la tendencia de los sistemas penales a centrar su atención en los derechos del imputado, dejando a la víctima en una situación de postergación. Desde esta postura, critica explícitamente el garantismo de Ferrajoli, ${ }^{75}$ al que vincula con ese problema. Parece, sin embargo, necesario contextualizar su planteamiento, reconociendo que su visión está muy influida por la experiencia Colombiana, y específicamente, por las situaciones de violencia organizada y conflicto armado, en las cuales se cometen delitos muy graves, con daños extremos a las víctimas y donde los imputados aparecen vinculados a aparatos de poder, por lo que resultan normalmente impunes. ${ }^{76}$

En cuanto a las propuestas, Sampedro-Arrubla considera necesario ampliar la participación de las víctimas en los procesos penales. El elemento central de su visión es la recuperación de la víctima como protagonista. ${ }^{77}$ Sin embargo, sus propuestas no están orientadas hacia el aumento de la punitividad del sistema, ni a ubicar a la víctima en un rol de acusador

tarde con la víctima. Apuntes", en: Primera Jornada de análisis y jurisprudencia de la Secretaría de Jurisprudencia y Biblioteca de la Excma. Cámara Nacional de Apelaciones en lo Criminal y Correccional, Buenos Aires: Cámara Nacional de Apelaciones en lo Criminal y Correccional, pp. 64 -87.

${ }^{70}$ MAIER, Segunda jornada de Derecho Penal, cit. nota n ${ }^{\circ}$ 62, p. 26.

${ }^{71}$ MAIER, Segunda jornada de Derecho Penal , cit. nota n ${ }^{\circ}$ 62, p. 27.

${ }^{72}$ MAIER, Segunda jornada de Derecho Penal, cit. nota n ${ }^{\circ}$ 62, p. 27.

${ }^{73}$ MAIER, Segunda jornada de Derecho Penal, cit. nota n ${ }^{\circ} 62$, p. 27.

${ }^{74}$ De hecho, ha sido el principal promotor de la llamada desmonopolización de la acción penal en Colombia, propósito para el cual integró una comisión especial creada por el Ministerio de Justicia de ese país por medio de la Resolución 0111 de 20 de febrero de 2012, la que no arribó a un resultado concreto y fue disuelta.

${ }^{75}$ SAMPEDRO-ARRUBLA, Julio, "Apuntes para una rehumanización de la justicia penal: en busca de un modelo re-creativo del sistema penal desde las víctimas", Vniversitas. ucls, Bogotá (Colombia), № 116 (juliodiciembre de 2008), p. 158.

${ }^{76}$ Corte Interamericana de Derechos Humanos, cit. nota ${ }^{\circ}$ 65, p. 158.

${ }^{77}$ Corte Interamericana de Derechos Humanos, cit. nota ${ }^{\circ}$ 65, p. 160. 
RIEGO, Cristián "La expansión de las facultades de las víctima en la Reforma Procesal Penal y con posterioridad a ella".

privado. Ellas se orientan más bien hacia la búsqueda de la reconciliación ${ }^{78}$ por medio de mecanismos como la mediación ${ }^{79}$ y otros, los cuales se alejan de la visión tradicional de la persecución en busca de una pena. Según su concepción, el proceso penal debe transformarse y pasar a ser una actividad de comunicación entre los involucrados en el conflicto. ${ }^{80}$

Nos parece que la discrepancia entre las dos posiciones expuestas es más aparente que real. Ambos autores pensaron originalmente que el protagonismo de la víctima ofrecía perspectivas favorables para el reemplazo de los castigos tradicionales por fórmulas reparatorias de diverso tipo. La diferencia entre sus posiciones actuales reside en que, mientras Maier parece haber perdido toda expectativa de que eso ocurra, SampedroArrubla parece conservarla.

Es probable que la diferencia entre ambos esté vinculada estrechamente con la realidad de sus países. En el caso de Argentina, el foco de atención está puesto en la criminalidad común, ${ }^{81}$ y en ese contexto la participación de la víctima está fuertemente vinculada a la pretensión de acentuar persecución de casos de ese tipo. En el caso de Colombia, en cambio, las principales preocupaciones tienen que ver con crímenes atroces derivados del crimen organizado y el conflicto armado, contexto que otorga justificación a la reivindicación del protagonismo de las víctimas frente a su invisibilización, y al rechazo a la impunidad de grupos de mucho poder responsables de los crímenes. ${ }^{82}$

\section{Conclusiones}

Las ideas y las orientaciones generales del reconocimiento de derechos de la víctima que se plasmaron en el código procesal penal estuvieron fuertemente atadas a tres ideas fundamentales: el reconocimiento de la reparación como un mecanismo útil y legítimo de solución al conflicto penal; a mejorar tanto el trato como el acceso a la información y la protección de las víctimas; y, por último, a reconocer su protagonismo en el conflicto penal permitiéndole participar como acusador adhesivo y, muy excepcionalmente, subsidiario.

Estas ideas no estaban vinculadas a la pretensión de ampliar la persecución y las posibilidades de punición, sino mas bien a las de reducirlas. La idea de la reparación aparecía como una posibilidad de reemplazar total o parcialmente algunas penas y la perspectiva de otorgar mayor protagonismo a la víctima y humanizar su participación en el proceso abría la posibilidad de recoger mejor la complejidad de los conflictos y encontrar mayor variedad de soluciones.

\footnotetext{
${ }^{78}$ Corte Interamericana de Derechos Humanos, cit. nota ${ }^{\circ} 65$, p. 167.

${ }^{79}$ Corte Interamericana de Derechos Humanos, cit. nota ${ }^{\circ} 65$, p. 163.

${ }^{80}$ Corte Interamericana de Derechos Humanos, cit. nota ${ }^{\circ}$ 65, p. 164.

${ }^{81}$ Ver, por ejemplo: CERRUTTI, Pedro, "El surgimiento de la 'inseguridad' como problema público político en la Argentina post-dictatorial", Revista Oficios Terrestres, 2011.

${ }^{82}$ Ver, por ejemplo, el reporte 2014 de Human Rights Watch sobre Colombia: http://www.hrw.org/worldreport/2014/country-chapters/colombia
} 
Con posterioridad, se ha generado un nuevo movimiento, centrado en el fortalecimiento de las facultades de la víctima en el proceso penal para promover la persecución. Esta nueva tendencia tiene un sesgo diferente. La reparación ha dejado de ser un objetivo central y la expectativa de nuevas formas de solución de los conflictos parece no ser relevante. La víctima aparece, en estas nuevas propuestas, como un agente orientado a maximizar la persecución, y las facultades que para ella se proponen están vinculadas al control de las facultades de no ejercicio de la persecución penal por parte de los fiscales o a la posibilidad de que la víctima ejerza directamente la persecución de modo subsidiario e incluso autónomo.

Este nuevo movimiento, a diferencia del primero, no tiene un origen en la doctrina ni en la cultura legal. Se trata más bien de ideas de sentido común, las cuales son fácilmente apoyadas por la población y que encuentran apoyo en funcionarios y en políticos, a partir de los cuales derivan en iniciativas de cambio bastante vigorosas. Dado lo anterior, no son ideas cuyas consecuencias hayan sido objeto de un análisis demasiado acabado.

Creemos que, a pesar de que existen algunos elementos que manifiestan continuidad entre ambos planteamientos, como por ejemplo la noción de la protección de la víctima o la de su participación y protagonismo en el proceso, ellos han adquirido matices diferentes. Mientras originalmente estuvieron vinculados a un reconocimiento simbólico y a la humanización del proceso, ahora también aparecen orientados a maximizar las posibilidades de persecución y punición.

Este cambio del sesgo con el que entendemos la idea de víctima y sus derechos es todavía un proceso en desarrollo. No es posible predecir si es que las distintas iniciativas de avance de la participación de las víctimas producirán cambios sustantivos en el funcionamiento de nuestro sistema de justicia penal. ¿Se consolidará la jurisprudencia del tribunal constitucional que reconoce la legitimidad del requerimiento previo de formalización o se abrirá la posibilidad de un ejercicio autónomo de la acusación particular? ¿Se implementará la reforma constitucional que otorga representación legal gratuita a grupos importantes de víctimas, masificando la presencia de querellantes en los juicios penales? ¿Prosperarán algunas iniciativas legales que otorguen mayores facultades a las víctimas para desafiar las decisiones de no perseguir del Ministerio Público?

La incertidumbre acerca de los cambios hace muy difícil perfilar un escenario futuro. Sin embargo, creemos que, de prosperar alguna combinación importante de los desarrollos descritos, es posible hacer algunas proyecciones. Habría que imaginar un sistema procesal penal en el que en un número importante de casos existan, además del fiscal, un abogado de la víctima que tenga múltiples oportunidades de desafiar las decisiones del fiscal e incluso, en algunos casos, conducir la persecución con autonomía del mismo.

De concretarse algunas de estas iniciativas, nuestro sistema se encontraría en una situación no planificada y respecto de la cual no existen tampoco parámetros de comparación, dado que a lo menos en los países de las culturas legales más influyentes dichos circunstancias no se producen. 
RIEGO, Cristián "La expansión de las facultades de las víctima en la Reforma Procesal Penal y con posterioridad a ella".

Es probable, además, que el Ministerio Público se debilitara de manera importante al perder la facultad que hoy tiene de controlar el acceso al proceso penal por medio de la formalización. Así, por ejemplo, es probable que sus posibilidades de negociar con el imputado disminuyeran, al no poder asegurar que la víctima no pueda perseguirlo privadamente.

El crecimiento de expresiones de persecución penal privada también provocaría cambios importantes, en aquellos casos en los que la víctima pudiese perseguir con autonomía respecto del fiscal. ¿No derivaría el proceso penal en una lógica de carácter más bien civil? Con las consecuencias que ello acarrea, por ejemplo el ampliar las posibilidades de negociación entre las partes más allá de los marcos definidos por la ley. 
Polít. crim. Vol. 9, № 18 (Diciembre 2014), Art. 11, pp. 668-690.

[http://www.politicacriminal.cl/Vol_09/n_18/Vol9N18A11.pdf]

\section{BIBLIOGRAFÍA}

AGUILERA BERTUCCI, Daniela, "La Participación de la Víctima en la Persecución Penal Oficial: Análisis a Partir de la Jurisprudencia del Tribunal Constitucional”, Revista Derecho Universidad Católica del Norte, vol. 18 n $^{\circ} 2$ (2011), pp. 51-72.

ASWORTH; Andrew, "Developments in the Public prosecutor's office in England and Wales", European Journal of Crime, Criminal Law and Criminal Justice, Vol. 8/3 (2000), pp. 257-282.

BAEZ, Danilo, "La eficacia del querellante en el juicio oral. Estudio empírico en el quinquenio de entrada en vigencia de la reforma procesal penal en la región metropolitana", en: FUENTES, Claudio (Coord.), Diez Años de la Reforma Procesal Penal en Chile, Santiago: Ediciones Universidad Diego Portales, 2011, pp. 191-241.

BORDALI SALAMANCA, Andrés, "La acción penal y la víctima en el Derecho chileno", Revista de Derecho de la Pontificia Universidad Católica de Valparaíso, n.37 (2011), en: http://www.scielo.cl/scielo.php?pid=S071868512011000200013\&script=sci_arttext [visitado el 24.09.2014].

"No hay ejercicio del derecho fundamental de acción en el proceso penal: Sentencia del tribunal constitucional que declaró inaplicable el artículo 230 del Código Procesal Penal", Rev. derecho (Valdivia), vol. 21, $\mathrm{n}^{\circ} 2$ (2008), en: http://www.scielo.cl/scielo.php?pid=S0718-09502008000200009\&script=sci_arttext [visitado el 24.09.2014].

BOVINO, Alberto, "La víctima como preocupación del abolicionismo penal", en: VV.AA., De los Delitos y del las Víctimas, Buenos Aires: Ad-Hoc, 1992, pp. 261-279.

BROWN, Kerstin, "Giving Victims a Voice: On the Problems of Introducing Victim Impact Statements in German Criminal Procedure [notes]", German Law Journal, Vol. 14, Issue 9 (September 2013), pp. 1889-1908.

BRANHAM, Lynn, The Law and Policy of Sentencing and Corrections, Saint Paul: Thomson/West, 2005.

BURNS, Peter, "Private Prosecutions in Canada: The Law and a Proposal for Change", McGill Law Journal, Vol. 21, № 2 (1975), pp 269-297.

CASTRO, Javier "La Víctima y el Querellante en la Reforma Procesal Penal", Revista de Derecho de la Pontificia Universidad Católica de Valparaíso, XXV (2004), pp $127-$ 141.

CRISTIE, Nils, "Los conflictos como pertenencia", en: VV.AA., De los Delitos y de las Víctimas, Buenos Aires: Ad-Hoc, 1992, pp. 157-182.

DIRK DUBER, Markus, "La víctima en el derecho penal estadounidense", Derecho, Proceso penal y Victimología, Mendoza: Ediciones Jurídicas Cuyo, 2003, pp. 23-58.

DOAK, Jonathan, "Victims rights in criminal trials: prospects for participation", Journal of Law and Society, vol. 32, n 2 (June 2005), pp 294-316.

DUCE, Mauricio, "El Ministerio Publico en la Reforma Procesal Penal en América Latina: visión general acerca del estado de los cambios", Sistemas Judiciales N 8 , (2005), pp 65-82.

, "La 'reforma de la reforma procesal penal': análisis de la gestación y contenidos de un proyecto de ley", en: VV.AA., Anuario de Derecho Público, Santiago: Universidad Diego Portales, 2013, pp. 110-144. 
RIEGO, Cristián "La expansión de las facultades de las víctima en la Reforma Procesal Penal y con posterioridad a ella".

DUCE, Mauricio; RIEGO, Cristian, "El Proceso Penal y los Derechos Humanos: las Víctimas de los Delitos en el Proceso Penal Chileno", en: DUCE, Mauricio y RIEGO, Cristián, El proceso penal y los derechos humanos, Santiago: Universidad Diego Portales, 1994.

ESSER, Albin, "Acerca del Renacimiento de la víctima en el procedimiento penal, tendencias nacionales e internacionales", en: VV.AA., De los delitos y de las Víctimas, Buenos Aires: Ad-Hoc, 1992, pp. 14-52.

GALDAMES ZELADA, Liliana, "Protección de la víctima, cuatro criterios de la Corte Interamericana de Derechos Humanos: interpretación evolutiva, ampliación del concepto de víctima, daño al proyecto de vida y reparaciones", Rev. chil. derecho, vol. 34, n 3 (2007), pp. 439-455.

GONZALEZ, Felipe, Sistema Interamericano de Derechos Humanos. Transformaciones y desafios, Valencia: Tirant lo Blanch, 2013.

GUZMAN, Nicolás, "El neopunitivismo en la jurisprudencia de la Corte Suprema de la Nación y de la Corte Interamericana de Derechos Humanos: un pronóstico incierto para el ne bis in idem y la cosa juzgada", Neopunitivismo y Neoinquisición, Buenos Aires: Ad-Hoc, 2008.

HORVITZ, María Inés; LÓPEZ, Julián, Derecho Procesal Penal Chileno Tomo I, Santiago: Editorial Jurídica de Chile, 2002.

Informe de la Comisión de Verdad y Reconciliación, Santiago, 1991, Tomo I.

KELLY, Deborah P., "Delivering Legal Services to Victims: an evaluation and prescription", Justice System Journal, Vol. 9 (1984), pp 62-86.

LAMBORN, LeRoy L., "Victim Participation in the Criminal Justice Process: the proposals for a Constitutional Amendment", Wayne Law Review, vol. 34 (19871988), pp. 125-220.

LARRAURI, Elena, "Victimología", en: VV.AA., De los Delitos y del las Víctimas, Buenos Aires: Ad-Hoc, 1992, pp. 281-316.

MAIER, Julio, Derecho Procesal Penal, Tomo I, fundamentos, Buenos Aires: Editores del Puerto, 1996.

, "La víctima y el sistema penal", en: VV.AA., De los delitos y de las Víctimas, Buenos Aires: Ad-Hoc, 1992.

MATURANA MIQUEL, Cristián; MONTERO LOPEZ, Raúl, Derecho Procesal Penal Tomo I, Santiago: Abeledo Perrot Legal Publishing, 2010, p. 296.

MEDINA, Cecilia, La Convención Americana: Teoría y Jurisprudencia, Santiago: Edición del Centro de Derechos Humanos de la Facultad de Derecho de la Universidad de Chile, 2005.

PARENTI, Pablo, "La Inaplicabilidad de normas de prescripción en la jurisprudencia de la Corte Interamericana de Derechos Humanos", en: VV.AA., Sistema interamericano de protección de los derechos humanos y derecho penal internacional, Montevideo: Konrad Adenauer Stiffung, 2010, pp. 221-229.

PASTOR, Daniel, "La deriva neopunitivista de organismos y activistas como causa del desprestigio actual de los derechos humanos", Jura Gentium Rivista di filosofía del diritto internazionale $e$ della politica globale, 2006, en: http://www.juragentium.org/topics/latina/es/pastor.htm [visitado el 24.09.2014]. 
Polít. crim. Vol. 9, № 18 (Diciembre 2014), Art. 11, pp. 668-690.

[http://www.politicacriminal.cl/Vol_09/n_18/Vol9N18A11.pdf]

, ¿Procesos penales solo para conocer la verdad? La experiencia argentina”, en:

PASTOR, Daniel (Dir.), Neopunitivismo y Neoinquisición, Buenos Aires: Ad-Hoc, 2008, pp. 367-428.

PÉREZ GIL, Julio, La Acusación popular, Tesis doctoral Universidad de Valladolid, Valladolid, 1997.

PIEDRABUENA RICHARD, Guillermo, "Cómo Proteger Mejor los Intereses de las Víctimas y de esta manera contribuir a la Disminución de la Delincuencia", Rev. chil. derecho, vol. $36, \quad \mathrm{n}^{\circ} 3$ (2009), pp. 671-677, en: http://www.scielo.cl/scielo.php?pid=S0718-34372009000300011\&script=sci_arttext [visitado el: 24.09.2014].

ROXIN, Claus, "La reparación en el sistema de los fines de la pena", en: VV.AA., De los Delitos y de las Víctimas, Buenos Aires: Ad-Hoc, 1992, pp. 129-156.

SAMPEDRO-ARRUBLA, Julio, "Apuntes para una rehumanización de la justicia penal: en busca de un modelo re-creativo del sistema penal desde las víctimas", Vniversitas. $u c l s, \mathrm{n}^{\circ} 116$ (julio diciembre de 2008), pp. 153-172.

SILVA SANCHEZ, Jesús-María, "Una crítica a las doctrinas penales de la lucha contra la impunidad y del derecho de la víctima al castigo del autor", Revista de Estudios de la Justicia, no 11 (2009), pp. 35-56.

VIDELA BUSTILLOS, Lino, "Los acuerdos reparatorios a la luz del concepto de reparación", Revista de Estudios de la Justicia, año 13 (2000), pp. 293-321. 